\title{
The Pattern and Maternal Outcome of Lower Genital Tract Injuries Among Women With Vaginal Deliveries in Calabar; A Niger Delta State of Nigeria
}

\author{
Charles Njoku*, Cajethan Emechebe, Christopher Iklaki, Felix Nnorom
}

\begin{abstract}
Objectives: ower genital tract injuries are associated with high maternal morbidity or mortality if severe, poorly managed or delayed in repair. It is a frequent complication of vaginal delivery. The aim of the present study was to determine the prevalence, demographic characteristics and pattern of spontaneous lower genital tract injuries and its relation to parity and place of delivery. Also, to determine the complications of lower genital tract injuries following vaginal delivery managed in UCTH, Calabar. Materials and Methods: This was a retrospective study of women managed for lower genital tract injuries at UCTH from 1 January, 2009 to 31 December, 2014. All women who sustained spontaneous lower genital tract trauma following vaginal delivery were studied.

Results: Out of 15526 total deliveries over the study period, 1413 women sustained lower genital tract injuries, giving a prevalence rate of $9.1 \%$. The most frequent lower genital tract injuries include first degree perineal tear $40.2 \%$, second degree perineal tear $18.3 \%$, peri-urethral tear $14.5 \%$ and cervical laceration $11.9 \%$. The prevalence of vaginal lacerations and third/fourth degree perineal tear were highest among primigravida, while cervical laceration was highest among primiparous. The most frequent morbidity observed were anemia $(44.8 \%)$ and postpartum hemorrhage (31.6\%). The maternal mortality of $0.68 \%$ was recorded and all were unbooked women who delivered outside UCTH.

Conclusion: The associated morbidity and mortality following lower genital tract injury in this study were high mostly among unbooked women who delivered outside the hospital. This can be reduced by health education, uptake of antenatal care and skilled attendance in labor.

Keywords: Cervix, Episiotomy, Genital tract, Obstetric delivery, Perineum, Vagina
\end{abstract}

\section{Introduction}

Birth trauma following vaginal delivery is associated with postpartum morbidity and mortality and the complication is directly related to the severity of perineal trauma (1). Human childbirth is seldom completed without occurrence of at least a slight injury to the birth canal which does not require suturing and sometimes, even deep tearing may occur in spite of skills and care (2). However, severe perineal injury is high where women deliver outside the hospital setting by unskilled birth attendant (2) as prevalent in developing countries such as Nigeria. Various lower genital tract injuries observed during vaginal delivery include; cervical laceration, vaginal laceration, episiotomy, perineal tears, vulva hematoma and para-urethral tears (2). The perineal tears or lacerations that require suture have increased gradually as the amount of episiotomies decrease. It was notice that where episiotomy is restricted, an increase in anterior vaginal trauma is seen (3). Historically, it was believed that episiotomy reduced spon- taneous perineal injury and anal sphincter tears by controlling the direction and extent of tissue damage (4). This is supported by a study in Spain where $87.5 \%$ of the diagnosed tears in spontaneous vaginal deliveries occurred in the absence of episiotomy and nulliparous women with spontaneous deliveries who did not undergo an episiotomy were 9 times more likely to present a tear than those who received an episiotomy (1). With advancement in the field of obstetrics, the incidence of severe perineal injury is decreased in developed countries were most of the deliveries are conducted in the hospital by skilled attendant (5). In the United States approximately 3 million women give birth vaginally each year and most of them experience trauma to the genital tract from episiotomy, spontaneous obstetric lacerations or both $(6,7)$. In the United Kingdom alone, approximately 1000 women per year will require repair following vaginal birth (8). Severe perineal tear which involve the anal sphincters and the rectal mucosa are identified in about $0.6 \%$ of vaginal deliveries in 
the United Kingdom and up to one third of women after their first vaginal delivery may develop occult sphincter injury (8). Rate of trauma was estimated at $41 \%$ of child bearing women in 2003, with significant morbidity (9). It is recognized that lower genital tract injuries are associated with macrosomia, instrumental deliveries, first vaginal birth, shoulder dystocia, midline episiotomy, female genital mutilation and deliveries by untrained birth attendants $(10,11)$. Instrumental delivery and midline episiotomy carry particularly large increase in the risk of extended trauma to the genital tract $(10,12)$.

Primary postpartum hemorrhage is an important complication of lower genital tract injuries and a significant contribution to maternal morbidity and mortality (13) usually when repair is delayed as in patients who delivered outside the health facility. Postpartum infection, perineal pain, discomfort and dysparunia may also complicate lower genital tract injuries (2). Vesico-vaginal fistula (VVF), third degree perineal tear and recto-vaginal fistula are other very serious complication of lower genital tract injury. Obstetric fistula accounts for $84.1 \%-100 \%$ of all VVF with prolonged obstructed labor being the main culprit (65.9\%-96.5\%) in Nigeria with the highest incidence in Northern Nigeria (14). The complication is mostly aggravated by marital disharmony, stigmatization, divorce and social exclusion.

Prevention of lower genital tract injuries requires multi-factorial approach (15). A randomized trial have documented that antenatal perineal massage during the last trimester of pregnancy may reduce the likelihood of perineal trauma and postpartum pain (16). One method that has been proven to be beneficial for women in labor is the skilled care in labor by trained birth attendant (17). This has been documented in trials over the past 30 years but this approach has not yet been implemented by many obstetric centers mostly in developing countries of the world. Although caesarean section may prevent lower genital tract trauma, this may be associated with higher morbidity and mortality (2).

There were few studies on lower genital tract injuries alone in our center and there were no recent studies towards determining the rate, pattern and outcome of lower genital tract injuries in our center. Therefore, the aim of this study is to determine the prevalence, demographic characteristics, pattern and complications of lower genital tract injuries at the University of Calabar Teaching Hospital, Calabar. The audit is important to obstetric care givers to know the types of lower genital tract injuries common, the severity and complications for better care of women in labor and to find ways to improve on the management outcome.

\section{Materials and Methods}

This retrospective cross-sectional study of lower genital tract injuries was carried out at UCTH, Calabar. The study covered a 6-year period between January 2009 and December 2014 in Maternity Annex, University of Calabar. All women who had vaginal delivery and sustained spontaneous lower genital tract injuries requiring suturing managed in UCTH were included in the study. Lower genital tract injuries involve injury to the perineum, vulva, vagina and the cervix. Women who sustained lower genital tract injuries from other causes such as episiotomy only and accident were excluded from the study. Women managed for lower genital tract injuries following child birth over the study period includes those who sustained the injuries during delivery in UCTH and those referred from outside UCTH from traditional birth attendance, churches, local maternity homes, home delivery, and rural health centers. Thorough evaluation of the clinical records regarding their labor duration, antenatal records, mode of delivery and types of injuries sustained were obtained. Demographic details, severity of obstetric injuries and complications were also obtained. For those who delivered outside UCTH, there labor characteristics were based on the documented history they volunteered at presentation and the birth weight of their neonate obtained when they were admitted. Those with incomplete records were excluded from the study. Out of 1413 cases of lower genital tract injuries managed over the study period, only 1320 case files were with complete data for analysis. Statistical analysis was done using Epi Info version 3.3.2 software and the results expressed using tables and percentages. A $P \leq .05$ was considered as statistically significant.

For the purpose of the study, perineal trauma was defined as any spontaneous damage to the genitalia (skin, muscle, and fascia) during childbirth. Classification of perineal tears was first, second, third and fourth degree, according to the classification of Royal College of Obstetricians and Gynecologists:

First degree: injury to perineal skin only; second degree: perineum and perineal muscles affected, but not involving the anal sphincter; third degree: injury to perineum involving the anal sphincter complex; and fourth degree: injury to perineum involving the anal sphincter complex and anal mucosa (18).

Unbooked woman is defined as a pregnant woman who has not attended any antenatal clinic session throughout the pregnancy with a skilled attendant (trained medical personnel) before presentation in labor (19). Booked pregnant woman is one who attended at least one antenatal clinic section during pregnancy by trained personnel (19).

\section{Results}

A total of 15526 deliveries were conducted during the study period, of which 1413 patients sustained lower genital tract injuries, giving a prevalence of $9.1 \%$ of total deliveries or 1: 10.9 deliveries.

Table 1 shows the socio-demographic characteristics of the women with lower genital tract injuries. The age range was 15-44 years. Majority of the patients were in the age group of 21-30 years (56.6\%), nulliparous women were $681(51.6 \%)$, fetal weight contributing to greatest injuries were in the range of $3.50-3.99 \mathrm{~kg}$ (45.7\%) and women who had spontaneous vaginal delivery were 1233 (93.4\%). Table 2 shows the type and frequency of lower genital tract 
injuries. First degree perineal tear (40.2\%), second degree perineal tear $(18.3 \%)$, para-urethral tear $(14.5 \%)$ and cervical laceration $(11.9 \%)$ were the leading types of lower genital tract injuries over the study period. Third degree perineal tears were $5(0.4 \%)$, while forth degree perineal tear was $7(0.5 \%)$.

Table 3 shows the relationship between parity and the type of lower genital tract injury.

Lower genital tract injury was commonest among nulliparous women accounting for 681 (51.6\%). Vaginal laceration $(8.4 \%)$, peri-urethral tear $(13.4 \%)$, second degree perineal tear $(21.7 \%)$ and third/forth degree perineal tear $(1.2 \%)$ were commonest among nulliparous women (para 0).

Also, cervical laceration (13.9\%) was commonest among para 1 while first degree perineal tear was commonest among para 5 or more $(62.2 \%)$.

Table 1. Socio-demographic Characteristics of the Women With Lower Genital Tract Injuries $(n=1320)$

\begin{tabular}{|c|c|c|}
\hline Demographic Factors & Number & $\%$ \\
\hline \multicolumn{3}{|l|}{ Age group } \\
\hline$\leq 20$ years & 296 & 22.4 \\
\hline $21-30$ years & 747 & 56.6 \\
\hline $31-40$ years & 219 & 16.6 \\
\hline$>40$ years & 58 & 4.4 \\
\hline \multicolumn{3}{|l|}{ Parity status } \\
\hline 0 & 681 & 51.6 \\
\hline 1 & 325 & 24.6 \\
\hline 2 & 154 & 11.7 \\
\hline 3 & 54 & 4.1 \\
\hline 4 & 69 & 5.2 \\
\hline$\geq 5$ & 37 & 2.8 \\
\hline \multicolumn{3}{|l|}{ Booking status } \\
\hline Booked & 824 & 62.4 \\
\hline Unbooked & 496 & 37.6 \\
\hline \multicolumn{3}{|l|}{ Place of birth } \\
\hline UCTH & 846 & 64.1 \\
\hline Outside UCTH & 474 & 35.9 \\
\hline \multicolumn{3}{|c|}{ Estimated duration of labor } \\
\hline Precipitate ( $\leq 3$ hours) & 11 & 0.8 \\
\hline Normal (4-12 hours) & 1114 & 84.4 \\
\hline Prolonged (>12 hours) & 195 & 14.8 \\
\hline \multicolumn{3}{|l|}{ Fetal weight } \\
\hline$\leq 2.5 \mathrm{~kg}$ & 16 & 1.2 \\
\hline $2.50-2.90 \mathrm{~kg}$ & 74 & 5.6 \\
\hline $3.0-3.49 \mathrm{~kg}$ & 316 & 23.9 \\
\hline $3.50-3.99 \mathrm{~kg}$ & 603 & 45.7 \\
\hline $4.0-4.49 \mathrm{~kg}$ & 302 & 22.9 \\
\hline$\geq 4.5 \mathrm{~kg}$ & 9 & 0.7 \\
\hline \multicolumn{3}{|l|}{ Mode of vaginal delivery } \\
\hline Spontaneous & 1233 & 93.4 \\
\hline Assisted breech & 26 & 2.0 \\
\hline Vacuum & 54 & 4.1 \\
\hline Forceps & 7 & 0.5 \\
\hline
\end{tabular}

Abbreviation: UCTH, University of Calabar Teaching Hospital.
Table 4 shows the relationship between the place of delivery and the types of lower genital tract injuries. More severe lower genital tract trauma such as cervical laceration, third/fourth degree perineal tear and multiple lacerations were significantly more among women who delivered outside UCTH.

Complications of lower genital tract injuries were higher among women who delivered outside our hospital than those who delivered in UCTH (Table 5). The leading complications observed over the study period were anemia (44.8\%), postpartum hemorrhage (31.6\%) and genital tract infections (11.6\%). These complications were statistically significantly among the patients who delivered outside UCTH.

\section{Discussion}

Genital tract injuries following vaginal delivery are common and a frequent complication of vaginal delivery. High frequency of genital tract trauma and its consequences results in a damaging child birth experience, delay in initiation of breastfeeding and adverse effects on the health of mothers (2). The prevalence of spontaneous lower genital tract injuries in this study is $9.1 \%$. This is slightly lower than $12.35 \%$ recorded by Kaur et al (10) in India and higher than 5.06\% in Pakistan (2). The reason for higher prevalence of lower genital tract injuries in the study in India may be due to inclusion of uterine rupture in the study. The difference could also be due to the different age groups, referral cases, place of delivery, skilled care in labor and labor/delivery technique resulting in genital tract trauma. Proper delivery technique and vigilant monitoring help a lot in reduction of obstetric trauma (20).

Lower genital tract injuries following vaginal birth was found to be related to age and parity as it was noticed that the prevalence was highest in age group of 21-30 years and least among women greater than 40 years. The high rate of injuries within the age group of 21-30 years may be due to the fact that these groups of women are the most prevalent in the delivery register and is the peak age of child bearing. The highest rate of spontaneous lower genital tract injuries was amongst women having their first vaginal birth and this may be due to rigid perineum and restrictive use of episiotomy resulting in high rate of spontaneous lower genital tract trauma during first vaginal delivery.

Table 2. Type and Frequency of Lower Genital Tract Injuries

\begin{tabular}{lcc}
\hline Types & Number & $\%$ \\
\hline 1st degree perineal tear & 531 & 40.2 \\
2nd Degree perineal tear & 242 & 18.3 \\
Para-urethral tear/anterior perineal tear & 191 & 14.5 \\
Cervical laceration & 157 & 11.9 \\
Vaginal laceration & 108 & 8.2 \\
Vulva hematoma & 9 & 0.7 \\
4th degree perineal tear & 7 & 0.5 \\
3rd degree perineal tear & 5 & 0.4 \\
Multiple injuries (>1 type) & 70 & 5.3 \\
\hline
\end{tabular}


Table 3. Pattern of Lower Genital Tract Injuries in Relation to Parity

\begin{tabular}{llcccccccc}
\hline & & \multicolumn{7}{c}{ Pattern of Lower Genital Tract Injuries } \\
\cline { 3 - 9 } Parity & Number (\%) & $\begin{array}{c}\text { No. of } \\
\text { Vaginal } \\
\text { Laceration } \\
\text { (\%) }\end{array}$ & $\begin{array}{c}\text { No. of } \\
\text { Cervical } \\
\text { Laceration } \\
(\%)\end{array}$ & $\begin{array}{c}\text { No. of 1st } \\
\text { Degree } \\
\text { Perineal Tear } \\
(\%)\end{array}$ & $\begin{array}{c}\text { No. of 2nd } \\
\text { Degree } \\
\text { Perineal } \\
\text { Tear (\%) }\end{array}$ & $\begin{array}{c}\text { No. of 3rd/4th } \\
\text { Degree } \\
\text { Perineal Tear } \\
(\%)\end{array}$ & $\begin{array}{c}\text { No. of } \\
\text { Vulva } \\
\text { Hematoma } \\
(\%)\end{array}$ & $\begin{array}{c}\text { No. of Peri- } \\
\text { Urethral } \\
\text { Tear (\%) }\end{array}$ & $\begin{array}{c}\text { No. of } \\
\text { Multiple } \\
\text { Tears (\%) }\end{array}$ \\
\hline p0 & $681(51.6)$ & $57(8.4)$ & $83(12.2)$ & $244(35.8)$ & $148(21.7)$ & $8(1.2)$ & $4(0.6)$ & $112(16.4)$ & $25(3.7)$ \\
P1 & $325(24.6)$ & $26(8.0)$ & $45(13.9)$ & $127(39.1)$ & $55(16.9)$ & $3(0.9)$ & $2(0.6)$ & $50(15.4)$ & $17(5.2)$ \\
p2 & $154(11.7)$ & $12(7.8)$ & $15(9.7)$ & $74(48.1)$ & $22(14.3)$ & $1(0.7)$ & $2(1.3)$ & $17(11.0)$ & $11(7.1)$ \\
p3 & $54(4.1)$ & $4(7.4)$ & $5(9.3)$ & $28(51.8)$ & $5(9.3)$ & $0(0.0)$ & $0(0.0)$ & $6(11.1)$ & $6(11.1)$ \\
p4 & $69(5.2)$ & $6(8.7)$ & $6(8.7)$ & $35(50.7)$ & $9(13.0)$ & $0(0.0)$ & $1(1.5)$ & $4(5.8)$ & $8(11.6)$ \\
$\geq$ p5 & $37(2.8)$ & $3(8.1)$ & $3(8.1)$ & $23(62.2)$ & $3(8.1)$ & $0(0.0)$ & $0(0.0)$ & $2(5.4)$ & $3(8.1)$ \\
Total & 1320 & $108(8.2)$ & $157(11.9)$ & $531(40.2)$ & $242(18.3)$ & $12(0.9)$ & $9(0.7)$ & $191(14.5)$ & $70(5.3)$ \\
\hline
\end{tabular}

Table 4. The Relationship Between the Place of Delivery and the Types of Lower Genital Tract Injuries

\begin{tabular}{|c|c|c|c|c|}
\hline \multirow{2}{*}{ Pattern of Lower Genital Tract Injuries } & \multirow{2}{*}{ Number (\%) } & \multicolumn{2}{|c|}{ Place of Delivery } & \multirow{2}{*}{$P$ Value } \\
\hline & & UCTH (\%) & Outside UCTH (\%) & \\
\hline Vaginal laceration & $108(8.2)$ & $46(42.6)$ & $62(57.4)$ & .000 \\
\hline Cervical laceration & 157 (11.9) & $59(37.6)$ & $98(62.4)$ & .000 \\
\hline $1^{\text {st }}$ degree perineal tear & $531(40.2)$ & $436(82.1)$ & 95 (17.9) & .000 \\
\hline $2^{\text {nd }}$ degree perineal tear & $242(18.3)$ & $138(57)$ & $104(43)$ & .011 \\
\hline $3^{\text {rd }} / 4^{\text {th }}$ degree perineal tear & $12(0.9)$ & $2(16.7)$ & $10(83.3)$ & .001 \\
\hline Vulva hematoma & $9(0.7)$ & $3(33.3)$ & $6(66.7)$ & .059 \\
\hline Peri-urethral tear & $191(14.5)$ & $133(69.6)$ & $58(30.4)$ & .084 \\
\hline Multiple tears & $70(5.3)$ & $29(41.4)$ & $41(58.6)$ & .000 \\
\hline Total & 1320 & 846 & 474 & \\
\hline
\end{tabular}

Abbreviation: UCTH, University of Calabar Teaching Hospital.

Table 5. Maternal Complications of Lower Genital Tract Injuries Versus Place of Delivery

\begin{tabular}{|c|c|c|c|c|}
\hline Complications/Place of Delivery & Total (\%) & Delivered in UCTH & Delivered Outside UCTH & $P$ Value \\
\hline Anemia; PCV <30 g/dl & $591(44.8)$ & 256 & 335 & .000 \\
\hline Postpartum hemorrhage & $417(31.6)$ & 108 & 309 & .000 \\
\hline Hemorrhagic shock & $169(12.8)$ & 24 & 145 & .000 \\
\hline Genital tract infection & $153(11.6)$ & 39 & 114 & .000 \\
\hline Wound breakdown & $107(8.1)$ & 15 & 92 & .000 \\
\hline Third degree perineal tear & $12(0.9)$ & 2 & 10 & .001 \\
\hline VVF & $2(0.15)$ & 0 & 2 & .058 \\
\hline RVF & $3(0.23)$ & 0 & 3 & .021 \\
\hline Death & $9(0.68)$ & 0 & 9 & .000 \\
\hline
\end{tabular}

Abbreviations: UCTH, University of Calabar Teaching Hospital; PCV, Packed cell volume; VVF, vesico-vaginal fistula; RVF, recto-vaginal fistula.

This finding was consistent with a study which showed that most child bearing women sustain significant trauma with higher rates consistently noted in the first vaginal birth and with instrumental delivery (21). Also there is high rate of lower genital tract injuries during the second delivery (24.6\%). The high rate of lower genital tract injuries amongst women having their second vaginal birth may be due to an unexplainable fright sustained after their first vaginal delivery. A hospital study in America on first vaginal delivery documented that the risk of a subsequent perineal tear was highest amongst those who had an episiotomy or perineal tear in the first vaginal birth in compar- ison with those of intact perineum (22).

Lower genital tract injuries in this study are high among women with labor duration of less than 12 hours and weight range of $3.0-3.9 \mathrm{~kg}$. The finding may be due to the fact that most women over the study period had normal vaginal delivery of normal weight babies and is similar to the finding by Kaur et al in India (10). Mode of delivery revealed that lower genital tract injuries is commonest among women with spontaneous vaginal delivery1233 (93.4\%), while instrumental delivery accounted for 61 (4.6\%). This may have been due to generally low incidence of instrumental delivery over the study period. Also lack 
of skills and training in the use of instrumental delivery may contribute to the decline in instrumental delivery as seen in this study. Reduction in instrumental deliveries may be clinically significant in reducing the incidence of spontaneous genital tract trauma and subsequent post delivery pain.

The most predominant lower genital tract injury was first degree perineal tear. Most first degree perineal tears are usually minor and most are self limiting requiring no suturing, however, when it is bleeding or deep, suturing is required. This finding is similar to a study in Zaria, Nigeria (23). Other common spontaneous lower genital tract trauma in this study includes second degree perineal tear, para-urethral tear and cervical laceration.

The relationship between parity and type of lower genital tract injuries revealed that vaginal laceration, para-urethral tear, second and third degree perineal tear were commonest among women having their first vaginal birth (para 0). The reason may be due to rigid perineum and high rate of unsupervised delivery outside the hospital. Cervical laceration was commonest among women having their second vaginal birth. The reason may be due to cervical scar disruption, unsupervised and premature bearing down resulting in cervical tear.

The most serious forms of lower genital tract injuries such as cervical laceration, vulva hematoma and third degree perineal tears were seen commonly among unbooked patients and women who delivered outside our hospital but referred to the hospital for management. The reason for this may be due to unsupervised or poorly supervised delivery, inability to recognize the obvious risk factors for lower genital tract injuries and poorly given episiotomy by unskilled birth attendant. This is similar to a study in Pakistan (2).

Anemia due to primary post partum hemorrhage was the most common complication accounting for 591 (44.8\%) and $169(12.8 \%)$ of these patient had hemorrhagic shock. Complications of lower genital tract injuries were higher among women who delivered outside the hospital than those who delivered in UCTH. The reason may be because these women sustained more serious lower genital tract injuries, delayed presentation to the hospital and were delivered by unskilled attendance in unhygienic environment with attendant infections. Other reasons for high complications of lower genital tract injuries among women who delivered outside the hospital may be due to inability to procure antibiotics on time or failure to take antibiotics mainly for financial reasons. Despite all emergency management and postoperative intensive care, 9 women $(0.68 \%)$ died due to irreversible shock after massive hemorrhage and septicemia. All the mortalities were among unbooked women who delivered outside UCTH. Third degree perineal tears occurred in 12 (0.9\%). Ten (83.3\%) were among unbooked women who delivered outside the hospital while 2 (16.7\%) occurred among women who delivered in our hospital. Among the two cases that occurred in our hospital, one was due to extension of poorly given episiotomy during delivery of a macrosomic baby while the other one occurred during forceps delivery. VVF and recto-vaginal fistula are common gynecological problems in developing countries because of the high incidence of obstetric complications (14). Following third degree perineal tear and prolonged labor, $2(0.15 \%)$ developed VVF and $3(0.23 \%)$ developed recto-vaginal fistula. These were the cases that had traumatic delivery outside the hospital and came late along with superimposed infection.

\section{Conclusion}

In conclusion, genital tract trauma is a common complication of vaginal birth leading to hemorrhage, shock and infection. The associated morbidity and mortality from lower genital tract injuries at our center is high usually among unbooked women who delivered outside the hospital than those who delivered in UCTH. Improvements in the quality of obstetric care available in our country and of their level of utilization by our pregnant women, through enhanced education and economic empowerment of women will go a long way in reducing the complications in our society. Skilled birth attendants in labor, vigilant labor monitoring, proper delivery technique and provision of emergency obstetric care services that are accessible and affordable will help a lot in reducing the rate of lower genital tract injuries and the complications.

\section{Ethical issues}

Approval was obtained from the Hospital Research and Ethics Committee, University of Calabar Teaching Hospital, Calabar, Nigeria before the study.

\section{Conflict of interests}

The authors declare that there is no conflict of interests regarding the publication of this paper.

\section{Finnacial support}

The researchers received no financial support or grant from any funding agency in the public and commercial sectors.

\section{Acknowledgments}

The authors declare that there is no acknowledgement.

\section{References}

1. Mora-Hervás I, Sánchez E, Carmona F, Espuña-Pons M. Perineal trauma in primiparous women with spontaneous vaginal delivery: Episiotomy or second degree perineal tear? Int J Women's Health Reprod Sci. 2015;3(2):84-8. doi: 10.15296/ijwhr.2015.16.

2. Khaskheli M, Balock S, Balock AS. Obstetrical trauma to the genital tract following vaginal delivery. J Coll Physicians Surg Pak. 2012;22(2):95-7. doi: 02.2012/ JCPSP.9597.

3. Carroli G, Belizan J. Episiotomy for vaginal birth. Cochrane Database Syst Rev 2000;(2):CD000081.

4. Fritel X, Schaal JP, Fauconnier A, Bertrand V, Levet C, Pigné A. Pelvic floor disorders 4 years after first delivery: a comparative study of restrictive versus 
systematic episiotomy. BJOG 2008;115(2):247-52. doi: 10.1111/j.1471-0528.2007.01540.x.

5. Hopkins LM, Caughey AB, Glidden DV, Laros RK Jr. Racial/ethnic difference in perineal, vaginal and cervical laceration. Am J Obstet Gynecol. 2005;193(2):455-9. doi: 10.1016/i.ajog.2004.12.007.

6. Hamilton BE, Martin JA, Sutton PD. Births: preliminary data for 2003. Natl Vital Stat Rep. 2004;53(9):1-18.

7. DeFrances CJ, Hall MJ. 2002 National Hospital discharge survey. Adv Data. 2004;(342):1-29.

8. Philips C, Monga A. Childbirth and the pelvic floor. "The gynecological consequences". Rev Gynecological Practice. 2005;5(1):15-22. doi: 10.1016/j. rigp.2004.09.002.

9. DeFrances CJ, Hall MJ, Podgornik MN. 2003 National Hospital discharge survey. Adv Data. 2005;359:1-20.

10. Kaur L, Dabhadkar S, Taralekar V, Wagh G. An observational prospective study of maternal genital tract injuries during vaginal delivery. Ind J Applied Res. 2012;2(3)342-50. doi: 10.15373/2249555x.

11. Dahlen H, Priddis H, Schmied V, et al. Trends and risk factors for severe perineal trauma during childbirth in New South Wales between 2000 and 2008: a population-based data study. BMJ Open. 2013;3(5):e002824. doi: 10.1136/ bmjopen-2013-002824.

12. Smith LA, Price N, Simonite V, Burns EE. Incidence of and risk factors for perineal trauma: a prospective observational study. BMC Pregnancy Childbirth. 2013;13:59. doi: 10.1186/1471-2393-13-59.

13. Poggy SG. Postpartum Hemorrhage \& Abnormal Puerperium. In: Decherney AH, Nathan L, Laufer N, Goodwin TM, Roman A, eds. Current Diagnosis and Treatment, Obstetrics \& Gynecology. 11th ed. USA: McGraw Hill; 2007:349-69.

14. Ijaiya AM, Rahman AG, Aboyeji AP, et al.
Vesicovaginal fistula: A review of Nigerian experience. West Afr J Med. 2010;29(5):293-8.

15. Alber LL, Borders N. Minimizing genital tract trauma and related pain following spontaneous vaginal birth. J Midwifery Women Health. 2007;52(3):246-53. doi: 10.106/j.jmwh.2006.12.008

16. Renfrew MJ, Hannah W, Albers L, Floyd E. Practices that minimize trauma to the genital tract in child birth: a systematic review of the literature. Birth. 1998;25(3):143-60.

17. Hodnett ED, Gates S, Hofmeryr L, Sakala C. Continuous support for women during childbirth. Cochrane Database Syst Rev. 2007;(3):CD003766.

18. The Management of third- and fourth degree perineal tears. Royal College of Obstetricians and Gynaecologists Green-top Guideline No 29. London: RCOG; 2007.

19. Iklaki CU, Inaku JU, Ekabua JE, Ekanem EE, Udo AE. Perinatal outcome in unbooked teenage pregnancies in the University of Calabar Teaching Hospital, Calabar, Nigeria. ISRN Obstet Gynecol. 2012;2012:246983. doi: 10.5402/2012/246983.

20. Albers LL, Anderson D, Cragin L, et al. Factors related to genital tract trauma in child birth. J Nurs Midwifery. 1996;41(4):269-76. doi: 10.1016/00912182(96)00042-0.

21. Lede RL, Belizan JM, Carroli G. Is routine use of episiotomy justified? Am J Obstet Gynecol. 1996;174(5):1399-402.

22. Alperin M, Krohn MA, Parvianen K. Episiotomy and increase in the risk of obstetriclaceration in subsequent vaginal delivery. Obstet Gynecol. 2008;11(6):12741278. doi: 10.1097/AOG.0b013e31816de899.

23. Adaji SE, Shittu OS, Nasir S. Lower genital tract trauma during spontaneous vaginal delivery. Nigerian Med Pract J. 2007;51(1/2):16-9.

Copyright (c) 2015 The Author(s); This is an open-access article distributed under the terms of the Creative Commons Attribution License (http://creativecommons.org/licenses/by/4.0), which permits unrestricted use, distribution, and reproduction in any medium, provided the original work is properly cited. 